\title{
Prováveis consequências do abrandamento da metodologia de erradicação do cancro cítrico no Estado de São Paulo
}

\author{
José Belasque Junior'1, José Carlos Barbosa ${ }^{2}$, Armando Bergamin Filho ${ }^{3}$ \& Cícero Augusto Massari \\ ${ }^{1}$ Fundo de Defesa da Citricultura - Fundecitrus, 14807 040, Araraquara, SP, Brasil; ${ }^{2}$ Departamento de Ciências Exatas, \\ Faculdade de Ciências Agrárias e Veterinárias, Universidade Estadual Paulista, 14870-000, Jaboticabal, SP, Brasil; \\ ${ }^{3}$ Departamento de Fitopatologia e Nematologia, ESALQ, Universidade de São Paulo, 13418-900, Piracicaba, SP, Brasil
}

Autor para correspondência: José Belasque Junior, e-mail: belasque@fundecitrus.com.br

\begin{abstract}
RESUMO
Recentemente a Secretaria de Agricultura e Abastecimento do estado de São Paulo abrandou os critérios relacionados à erradicação do cancro cítrico. Em abril de 2009 mais de 99,8\% dos talhões comerciais de laranjeiras doces estavam livres da doença em São Paulo. Abrandar a metodologia de erradicação significa comprometer esse elevado nível de sanidade dos pomares e a competitividade da citricultura, com reflexos negativos financeiros e ambientais. Diante desses fatos sugere-se: a) que a erradicação da doença volte a ser feita como anteriormente utilizada; ou b) a adoção de uma nova metodologia de erradicação, mais efetiva na supressão da doença, quando em novos levantamentos amostrais de cancro cítrico em São Paulo forem encontradas incidências de talhões comerciais com a doença superiores a $0,36 \%$. Essa incidência foi calculada comparando-se pelo teste de Duncan $(P \leq 0,05)$ os levantamentos amostrais de cancro cítrico realizados de 1999 a 2009. A diferença mínima significativa encontrada foi de 0,28 . A menor incidência do cancro cítrico em São Paulo foi de $0,08 \%$, observada em 2001. Dessa forma, como alternativa, propõe-se a adoção de uma metodologia mais drástica de erradicação do cancro cítrico quando em um novo levantamento amostral for detectado mais que $0,36 \%$ de talhões comerciais com cancro cítrico.

Palavras-chave: Xanthomonas citri subsp. citri, defesa fitossanitária, citros.
\end{abstract}

\begin{abstract}
Probable consequences of the mitigation of citrus canker eradication methodology in São Paulo state

Recently the São Paulo state government mitigated its citrus canker eradication methodology adopted since 1999. In April 2009 at least $99.8 \%$ of commercial sweet orange orchards were free of citrus canker in São Paulo state. Consequently the mitigation of the eradication methodology reduced the high level of safety and the competitiveness of the citrus production sector in São Paulo state, Brazil. Therefore we suggest the re-adoption of the same eradication methodology of citrus canker adopted in São Paulo from 1999 to 2009, or the adoption of a new methodology, effective for citrus canker suppression, because in new sample surveys citrus canker was detected in $>0.36 \%$ of affected orchards. This incidence threshold was calculated by using the Duncan test $(P \leq 0.05)$ to compare the yearly sample surveys conducted in São Paulo state to estimate citrus canker incidence between 1999 and 2009. The calculated minimum significant level was $0.28 \%$ among sample surveys and the lowest citrus canker incidence in São Paulo state was 0.08\%, occurring in 2001. Thus, as an alternative, we suggest the adoption of a new eradication methodology for citrus canker suppression when a new sample survey detected $>0.36 \%$ of affected orchards in São Paulo state, Brazil.
\end{abstract}

Key words: Xanthomonas citri subsp. citri, phytosanitary defense, citrus.

Dentre alguns dos desafios enfrentados pela citricultura paulista está o cancro cítrico, doença bacteriana incitada por Xanthomonas citri subsp. citri (sin. X. axonopodis pv. citri). A primeira ocorrência no Brasil foi em 1957, no município de Presidente Prudente, São Paulo (Amaral, 1957; Bitancourt, 1957). Medidas de exclusão e erradicação foram adotadas regionalmente já nesse mesmo ano e foi iniciada em São Paulo uma campanha de erradicação do cancro cítrico, que permanece em execução até os dias atuais (Belasque Jr. et al., 2009; Massari \& Belasque Jr., 2006). Apesar dos esforços iniciais, a doença foi posteriormente encontrada em outros estados (Goiás, Mato Grosso, Mato Grosso do Sul, Minas Gerais, Paraná, Santa
Catarina, Rio Grande do Sul e Roraima) provavelmente em razão da movimentação de material vegetal infectado (Amaral, 1957). Acredita-se que a introdução do cancro cítrico no Brasil tenha ocorrido alguns anos antes da primeira detecção, quando materiais propagativos foram importados da Ásia (Rossetti, 1977).

Recentemente a Secretaria de Agricultura e Abastecimento do Estado de São Paulo (SAA/SP) alterou os critérios relacionados à erradicação do cancro cítrico. Primeiramente foi aprovada, em 25/06/2009, a Resolução SAA 43 determinando que sua Coordenadoria de Defesa Agropecuária (CDA) promova a erradicação de plantas contaminadas, e das suspeitas de contaminação, baseada na 
Prováveis consequências do abrandamento da metodologia de erradicação do cancro cítrico...

Portaria 291, de 23/07/1997, do Ministério da Agricultura, Pecuária e Abastecimento (MAPA). Essa Portaria 291 descreve quatro métodos, alternativos, de erradicação de plantas em áreas infestadas com cancro cítrico e é válida em todo território nacional. Esses métodos são: i. Método -1: eliminação da planta ou plantas contaminadas e das demais contidas num raio mínimo de 30 metros, consideradas suspeitas de contaminação; ii. Método 2: eliminação da planta ou plantas contaminadas e poda drástica das demais contidas num raio mínimo de 30 metros, consideradas suspeitas de contaminação; iii. Método -3: eliminação da planta ou plantas contaminadas e desfolha química das demais contidas num raio mínimo de 30 metros, consideradas suspeitas de contaminação; e iv. Método -4: poda drástica da(s) planta(s) contaminada(s) e pulverização no raio perifocal mínimo de 30 metros com calda cúprica na concentração de 0,1\% de cobre metálico; repetir a pulverização a cada brotação nova.

Após a divulgação da Resolução SAA 43/2009 também foi aprovada a Portaria CDA 11/2009, a qual revogou simultaneamente a Portaria CDA 28/2007 e a Resolução CEE-CANECC/SP 01/2000. Anteriormente a essas alterações realizadas pela SAA a eliminação de todas as plantas dos talhões comerciais infestados com cancro cítrico era obrigatória quando a incidência de plantas sintomáticas detectadas era superior a $0,5 \%$, como determinado na Resolução CEE-CANECC/SP 01/2000. Para incidências iguais ou menores que $0,5 \%$, apenas as plantas sintomáticas detectadas, e as demais contidas num raio mínimo de trinta metros, eram eliminadas. Anteriormente a essa metodologia (0,5\%), já se aplicava o Método 1 descrito na Portaria 291/1997 que voltou a vigorar em São Paulo em 2009 quando da aprovação da Portaria CDA 11/2009. Em resumo, a metodologia de erradicação do cancro cítrico em São Paulo foi abrandada, voltando a ser a mesma utilizada anteriormente a 1999 .

A erradicação do cancro cítrico baseada na incidência de plantas doentes foi adotada por quase dez anos em São Paulo - de Julho de 1999 a Junho de 2009, o que permitiu a manutenção de baixas incidências da doença no estado de São Paulo (Tabela 1). Como citado anteriormente, essa metodologia de erradicação foi adotada em 1999 e fezse necessária em razão do incremento na incidência e da severidade do cancro cítrico após o aparecimento do inseto conhecido como minador dos citros (Phyllocnistis citrella Stainton - Lepdoptera: Gracillariidae: Phyllocnistinae) em São Paulo (Prates et al., 1996). Mais informações podem ser obtidos em diferentes trabalhos (Belasque Jr. et al., 2005; Christiano et al., 2007; Christiano et al., 2007; Gottwald et al., 2002, 2007; Jesus Jr. et al., 2006). Após a introdução dessa praga, a adoção do referido raio de erradicação mostrou-se incapaz de conter a doença, fato observado tanto em São Paulo quanto na Flórida (EUA). A erradicação do cancro cítrico no novo patossistema Xanthomonas citri subsp. citri - citros - Phyllocnistis citrella é parcialmente possível, adotando-se o raio de trinta metros, quando da detecção de talhões muito recentemente infestados com a doença, ou seja, quando ainda há somente o foco primário da doença no talhão. Além disso, eliminando-se apenas as plantas doentes, independentemente da incidência da doença, permanecem no talhão plantas infectadas, porém não detectadas nas inspeções ou ainda assintomáticas, resultando na continuidade da doença na área e na disseminação da mesma para as demais plantas e pomares vizinhos. Como exemplo, entre 1996, ano da primeira detecção do minador dos citros em São Paulo, e 1999, quando do início da adoção da metodologia do $0,5 \%$, aproximadamente $80 \%$ dos pomares encontrados com cancro cítrico não eram saneados com a aplicação do raio de trinta metros e voltavam a ser encontrados com a doença meses depois da primeira erradicação parcial de plantas. Na presença desse inseto a adoção de um raio de erradicação de trinta metros exige inspeções muito frequentes (provavelmente mensais) e a imediata eliminação das plantas sintomáticas e das demais suspeitas de infecção contidas no citado raio de erradicação. Assim, para se manter a doença em baixos níveis, como os identificados em São Paulo nos últimos dez anos, as inspeções mensais demandariam o emprego de milhares de inspetores em todo estado, como ocorrido em 1999, quando foram utilizados os serviços de 4.000 inspetores.

A adoção de um raio de erradicação pressupõe a eliminação das plantas foco (sintomáticas detectadas nas inspeções) e das demais suspeitas de infecção (sintomáticas não detectadas, plantas em período de incubação e plantas sadias), dispostas ao redor da planta foco. As distâncias de disseminação da doença são o fator preponderante na definição da estratégia a ser adotada na erradicação do cancro cítrico (Gottwald et al., 2002). Como demonstrado por Belasque Jr. (2005), Belasque Jr. et al. (2007) e Gottwald et al. (2002, 2007), a disseminação do cancro cítrico, determinada pelas distâncias entre plantas doentes, dá-se frequentemente a distâncias de dezenas a centenas de metros, podendo algumas vezes atingir quilômetros de distância. Portanto, o controle efetivo do cancro cítrico em São Paulo exige a adoção de raios de erradicação superiores a trinta metros ou a erradicação de talhões inteiros quando apresentarem focos da doença, como determinado pelo critério de erradicação baseado na incidência de $0,5 \%$ de plantas sintomáticas, anteriormente utilizado no estado. Assim, o abrandamento da metodologia de erradicação adotada pela SAA poderá resultar, em apenas alguns anos, na completa perda de controle da doença em São Paulo e, consequentemente, num novo cenário caracterizado pela convivência com a doença, como atualmente ocorre nos Estados do Paraná, Santa Catarina e Rio Grande do Sul, no Brasil e no Estado da Flórida, nos Estados Unidos.

O Estado de São Paulo é o maior produtor mundial de citros e o maior exportador mundial de suco de laranja (Neves et al., 2007). Essa condição foi alcançada em razão, principalmente, do clima e solo favoráveis, disponibilidade de mão-de-obra e terras relativamente baratas, baixíssima incidência do cancro cítrico e ausência do huanglongbing (HLB) (essa última até aproximadamente o final da década 
de 90), doenças reconhecidas mundialmente como as duas mais importantes da cultura. Caso o cancro cítrico se torne endêmico perde-se vantagens competitivas essenciais à cadeia produtiva de citros, como exemplos: i. praticamente todos os citricultores do estado teriam seus custos de produção aumentados, em razão da necessidade de pulverizações adicionais com bactericidas cúpricos e da implantação de quebra-ventos arbóreos (Behlau et al., 2007, 2008, 2010); ii. os citricultores paulistas teriam quedas em suas produtividades, provocadas pela queda de folhas e frutos sintomáticos (Behlau et al., 2008, 2010); iii. a produção de cítricos para comércio de frutas in natura, de regiões em que o cancro cítrico é endêmico, sofre severas e restritivas imposições, por parte de países e regiões importadores livres do patógeno, e iv. variedades e espécies cítricas economicamente importantes na citricultura paulista atual dificilmente seriam produzidas, como a laranjeira doce 'Hamlin', por exemplo, em razão da alta suscetibilidade ao cancro cítrico (Leite Jr. et al., 1987; Leite Jr. \& Mohan, 1990.

O manejo do cancro cítrico, como realizado nos Estados do sul do Brasil (Paraná, Santa Catarina e Rio Grande do Sul) e na Flórida (EUA), exige pulverizações mensais com cúpricos no período coincidente de brotações ou frutos jovens e precipitações (Behlau et al., 2010). As aplicações desses defensivos protetores não promovem o controle efetivo da doença, e como já citado, representam um custo de produção adicional. Além disso, mesmo com sucessivas aplicações de defensivos, há perdas significativas de produção resultantes, principalmente, da queda de frutos com sintomas (Behlau et al., 2008, 2010). Considerando a baixíssima incidência da doença no Estado de São Paulo, - atualmente mais de 99,9999\% das plantas não estão infectadas pela bactéria causadora do cancro cítrico -, a melhor estratégia de controle é a erradicação de plantas doentes e das suspeitas de infecção. A eliminação ou poda somente das plantas com sintomas, além de não permitir um controle adequado da doença, reduziria a competitividade da citricultura, pois resultaria na contaminação de todo Estado em apenas alguns anos. A contaminação da maioria dos pomares do Estado com cancro cítrico exigiria, obrigatoriamente, gastos anuais de dezenas de milhões de reais com pulverizações visando o controle da doença. Esse custo adicional de controle seria pago por praticamente todos os citricultores de São Paulo.

Desde 1999, numa colaboração entre o Fundo de Defesa da Citricultura (Fundecitrus) e a Faculdade de Ciências Agrárias e Veterinárias da UNESP, Campus de Jaboticabal SP, um levantamento amostral é realizado anualmente em todo o parque citrícola, cujo objetivo é determinar a incidência do cancro cítrico nas diferentes regiões produtoras. A média da incidência da doença em 2009 foi de $0,14 \%$ de talhões comerciais infestados, o que mostra que mais de $99,8 \%$ dos talhões estão livres da doença (Tabela 1). Abrandar a metodologia de erradicação significa comprometer esse elevado nível de sanidade dos pomares, a
TABELA 1 - Incidência (\%) de talhões comerciais com cancro cítrico detectados no Estado de São Paulo entre 1999 e 2009 e diferenças significativas entre esses anos considerando o teste de Duncan $(P \leq 0,05)$

\begin{tabular}{cc}
\hline \hline Ano & Talhões comerciais infestados $\mathbf{( \% )}$ \\
\hline 1999 & $0,70 \mathrm{a}$ \\
2000 & $0,27 \mathrm{~b}$ \\
2001 & $0,08 \mathrm{~b}$ \\
2002 & $0,11 \mathrm{~b}$ \\
2003 & $0,20 \mathrm{~b}$ \\
2004 & $0,13 \mathrm{~b}$ \\
2005 & $0,11 \mathrm{~b}$ \\
2006 & $0,19 \mathrm{~b}$ \\
2007 & $0,10 \mathrm{~b}$ \\
2008 & $0,17 \mathrm{~b}$ \\
2009 & $0,14 \mathrm{~b}$ \\
\hline
\end{tabular}

competitividade da citricultura, e provavelmente condenar os citricultores paulistas à convivência com a doença, com reflexos negativos, financeiros e ambientais, para todos os citricultores paulistas.

Diante desses fatos sugere-se, prioritariamente, que a erradicação da doença volte a ser feita com o critério baseado na incidência de plantas sintomáticas detectadas $(0,5 \%)$. Essa metodologia de erradicação e as contínuas inspeções empregadas em todo estado entre 1999 e 2009 foram os dois aspectos fundamentais para se atingir o alto nível de sanidade atual do parque citrícola paulista. Na impossibilidade do retorno imediato à legislação adotada entre 1999 e 2009, sugere-se esse retorno (ou a adoção de qualquer outro critério efetivo de supressão da doença, que não a manutenção do raio de trinta metros), quando a incidência do cancro cítrico no estado atingir níveis estatisticamente superiores à menor incidência identificada com a adoção do $0,5 \%$ como critério de erradicação. Objetivando determinar esse nível, compararam-se estatisticamente pelo teste de Duncan $(P \leq 0,05)$ os levantamentos amostrais de cancro cítrico realizados de 1999 a 2009. Os pomares comerciais amostrados em cada ano foram considerados como "repetições", e os anos como "tratamentos". Dessa forma, calculou-se a diferença mínima significativa (d.m.s.), a qual foi utilizada para comparar as incidências da doença no estado desde 1999. O valor calculado da d.m.s. foi 0,28 , e as diferenças entre os anos estão apresentadas na Tabela 1. Dessa forma, considerando a menor incidência, observada em $2001(0,08 \%)$, propõe-se como nível a incidência mínima de $0,36 \%(0,28+0,08)$. Esse valor representa a incidência mínima observada da doença no estado, nos últimos onze anos, mais a d.m.s. calculada, a qual é dependente das incidências médias de todos os anos e representa quais incidências diferem estatisticamente entre si. Assim, o nível de ação indica o ponto a partir do qual a incidência de cancro cítrico torna-se estatisticamente superior à menor incidência obtida com a adoção do critério de $0,5 \%$, entre 1999 e 2009. 
Prováveis consequências do abrandamento da metodologia de erradicação do cancro cítrico...

A campanha de erradicação do cancro cítrico vem sendo aplicada não somente em pomares comerciais, mas também em pomares domésticos (não comerciais) nas zonas rural e urbana das regiões mais infestadas do Estado de São Paulo. A metodologia de erradicação baseada no $0,5 \%$ também foi aplicada em pomares domésticos presentes na zona rural (Resolução CEE-CANECC/SP 03/2000), de 2000 a 2007, mas foi revogada pela Portaria CDA 28, de 18/09/2007. Essa última Portaria determinava a aplicação de um raio de 120 metros, restrito ao imóvel infestado, quando da detecção de plantas doentes em pomares domésticos. Esse, de fato, foi o primeiro abrandamento na erradicação do cancro cítrico em São Paulo após a implantação do 0,5\% em 1999. Já em residências na zona urbana, a Resolução CEECANECC/SP 01/2000 determinava a eliminação de todas as plantas cítricas quando da detecção de ao menos uma delas doente. Como relatado, essa Resolução foi revogada pela Resolução SAA 43/2009. Assim, objetivando um efetivo controle da doença em São Paulo, sugere-se maior rigor não somente para os casos da doença em pomares comerciais, mas também em pomares domésticos e em residências localizadas na zona urbana.

\section{REFERÊNCIAS BIBLIOGRÁFICAS}

Amaral SF (1957) Providências para a erradicação do cancro cítrico. O Biológico 23:112-123.

Behlau F, Belasque Jr. J, Bergamin Filho A, Graham JH, Leite Jr. RP, Gottwald TR (2008) Copper sprays and windbreaks for control of citrus canker on young orange trees in southern Brazil. Crop Protection 27:807-813.

Behlau F, Belasque Jr. J, Bergamin Filho A, Leite Jr. RP (2007) Incidência e severidade de cancro cítrico em laranja 'Pêra Rio' sob condições de controle e proteção com quebra-vento. Fitopatologia Brasileira 32:311-317.

Behlau F, Belasque Jr. J, Graham J H, Leite Jr. RP (2010) Effect of frequency of copper applications on control of citrus canker and the yield of young bearing sweet orange trees. Crop Protection 29:300-305.

Belasque Jr. J (2005) Dinâmica espacial do cancro cítrico, interação com a larva minadora dos citros (Phyllocnistis citrella) e diversidade genética do seu agente causal (Xanthomonas axonopodis pv. citri). Tese de Doutorado. Universidade de São Paulo. Piracicaba SP.

Belasque Jr. J, Gimenes-Fernandes N, Massari CA (2009) O sucesso da campanha de erradicação do cancro cítrico no estado de São Paulo, Brasil. Summa Phytophthologica 35:91-92.
Belasque Jr. J, Parra-Pedrazzoli AL, Rodrigues Neto J, Yamamoto PT, Chagas MCM, Parra JRP, Vinyard BT, Hartung JS (2005) Adult citrus leafminers (Phyllocnistis citrella) are not efficient vectors for Xanthomonas axonopodis pv. citri. Plant Disease 89:590-594

Belasque Jr. J, Spósito MB, Bassanezi RB, Amorim L, Bergamin Filho A, Gottwald TR (2007) Epidemias de cancro cítrico. II Workshop de epidemiologia de doenças de plantas. ESALQ, Universidade de São Paulo. pp. 96-99.

Bitancourt AA (1957) O cancro cítrico. O Biológico 23:101-111.

Christiano RSC, Dalla Pria M, Jesus Jr. WC, Parra JRP, Amorim L, Bergamin Filho A (2007) Effect of citrus leaf-miner damage, mechanical damage and inoculum concentration on severity of symptoms of Asiatic citrus canker in Tahiti lime. Crop Protection 26:59-65.

Christiano RSC, Dalla Pria M, Jesus Jr. WC, Amorim L, Bergamin Filho, A. (2009). Modelling the progress of Asiatic citrus canker on Tahiti lime in relation to temperature and leaf wetness. European Journal of Plant Pathology 124:1-7.

Gottwald TR, Bassanezi RB, Amorim L, Bergamin Filho A (2007) Spatial pattern analysis of citrus canker-infected plantings in São Paulo, Brazil, and augmentation of infection elicited by the asian leafminer. Phytopathology 97:674-683.

Gottwald TR, Sun X, Riley T, Graham JH, Ferrandino F, Taylor EL (2002) Geo-referenced spatiotemporal analysis of the urban citrus canker epidemic in Florida. Phytopathology 92:361-377.

Jesus Jr. WC, Belasque Jr. J, Amorim L, Christiano RSC, Parra JRP, Bergamin Filho A (2006) Injuries caused by citrus leafminer (Phyllocnistis citrella) exacerbate citrus canker (Xanthomonas axonopodis pv. citri) infection. Fitopatologia Brasileira 31:277283.

Leite Jr. RP, Mohan SK (1990) Integrated management of the citrus bacterial canker disease caused by Xanthomonas campestris pv. citri in the State of Parana, Brazil. Crop Protection 9:3-7.

Leite Jr. RP, Mohan SK, Pereira ALG, Campacci CA (1987) Integrated control of citrus canker: effect of genetic resistance and application of bactericides. Fitopatologia Brasileira 12:257-263.

Massari, CA, Belasque Jr. J (2006) A campanha de erradicação do cancro cítrico no Estado de São Paulo - Situação atual e contaminação em viveiros. Laranja 27:41-55.

Neves MF, Lopes FF, Trombin VG, Amaro AA, Neves EM, Jank MS (2007) Caminhos para a citricultura. São Paulo SP. Editora Atlas S.A.

Prates HS, Nakano O, Gravena S 1996. Minadora das folhas dos citros Phyllocnistis citrella, Stainton, 1856. Campinas SP. CATI, Comunicado Técnico, 129.

Rossetti VV (1977) Citrus canker in Latin America: A review. Proceedings of the International Society of Citriculture 3:918923.
TPP 84 - Recebido 4 Março 2010 - Aceito 29 Setembro 2010 Editor de Seção: Marcos A. Machado 